\title{
Splenic Neoplasm
}

National Cancer Institute

\section{Source}

National Cancer Institute. Splenic Neoplasm. NCI Thesaurus. Code C3383.

A benign or malignant neoplasm that affects the spleen. Representative examples

include hemangioma, lymphoma, splenic involvement by leukemia, and angiosarcoma. 